\title{
Optically stimulated luminescence ages for human occupation during the penultimate glaciation in the western Loess Plateau of China
}

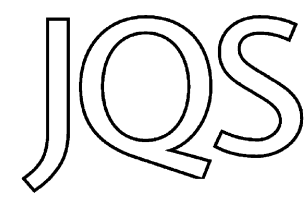

\author{
XIAOMEI NIAN, ${ }^{1 *}$ FENG LI, ${ }^{2}$ FUYOU CHEN, ${ }^{2}$ WEIGUO ZHANG, ${ }^{1}$ YUCHAO ZHAO, $^{3}$ JING ZHOU ${ }^{4}$ and XING GAO ${ }^{2}$ \\ ${ }^{1}$ State Key Laboratory of Estuarine and Coastal Research, East China Normal University, Shanghai 200062, China \\ ${ }^{2}$ Key Laboratory of Vertebrate Evolution and Human Origins of Chinese Academy of Sciences, Institute of Vertebrate Paleontology \\ and Paleoanthropology, Chinese Academy of Sciences, Beijing 100044, China \\ ${ }^{3}$ Department of Anthropology, University of Michigan, Ann Arbor, MI 48109, USA \\ ${ }^{4}$ Gansu Provincial Institute of Archaeology and Cultural Relics, Lanzhou 730050, China
}

Received 28 September 2015; Revised 9 September 2016; Accepted 24 October 2016

\begin{abstract}
The chronology of few Palaeolithic sites in the Loess Plateau of China has been well investigated for the Middle Pleistocene. In this study, the Yangshang Palaeolithic site with significant archaeological remains, located in Gansu Province of the western Chinese Loess Plateau, was dated using blue-stimulated optically stimulated luminescence (OSL) and infrared stimulated luminescence (IRSL) techniques on eight medium-grained $(45-63 \mu \mathrm{m})$ quartz and polymineral samples through the Palaeolithic sequence. Except for one sample from the upper cultural layer $(55 \pm 3 \mathrm{ka})$, age estimates obtained by quartz OSL dating exceed its upper datable limit, and so an elevated temperature post-IR IRSL SAR protocol was used on $45-63 \mu \mathrm{m}$ polymineral grains to derive a numerical chronology for the site. The luminescence ages of seven samples from six cultural layers lie between $104 \pm 5$ and $220 \pm 11 \mathrm{ka}$; for the three main cultural layers the results varied from $149 \pm 9$ to $186 \pm 10 \mathrm{ka}$, consistent with the presently observed stratigraphy. The dating results shown that early hominins may have occupied this region in the western Loess Plateau of China during Marine Isotope Stage (MIS) 7, early glacial MIS 6 and early interglacial MIS 5, reflecting their ability to adapt to variable environments.
\end{abstract}

Copyright (C) 2016 John Wiley \& Sons, Ltd.

KEYWORDS: Chinese Loess Plateau; chronology; optically stimulated luminescence (OSL) dating; Palaeolithic; Yangshang.

\section{Introduction}

The loess-palaeosol sequences in the Chinese Loess Plateau contain continuous records of the changing climate through multiple glacial-interglacial cycles and have been accepted as an excellent archive of global palaeoclimatic cycles (e.g. Liu, 1985; An et al., 1990; Ding et al., 2002). Furthermore, the various strata of the loess and palaeosol are an important repository for Palaeolithic human and faunal remains, from which a record of early human occupation can be reconstructed (Morgan et al., 2011). As is often the case with reconstructions of the past, a reliable chronological framework is critical before they can be fully exploited. Optically stimulated luminescence (OSL) dating, which was developed in the mid-1980s (Huntley et al., 1985) and can be applied to estimate the depositional age or burial age of sediments (Aitken, 1998), is an ideal technique for establishing the ages of loess-palaeosol deposits (e.g. Roberts, 2008; Rhodes, 2011).

The Yangshang Early Palaeolithic site $\left(34^{\circ} 59^{\prime} 50.13^{\prime \prime} \mathrm{N}, 106^{\circ}\right.$ $10^{\prime} 13.79^{\prime \prime} \mathrm{E}, 1816 \mathrm{~m}$ asl) (Fig. 1 ) is $<65 \mathrm{~km}$ from Tianshui city in the south-east part of Gansu Province and located in the western loess plateau of China. The site was discovered during a Palaeolithic survey project in 2007 in the eastern Longxi Basin of Gansu, and was temporarily named as Zhangjiachuan locality 2 (ZLJ02) at that time (Morgan et al., 2011). Morgan et al. (2011) reported three OSL dates based on quartz from the profile at the Yangshang site: two samples at the top were dated to between ca. 40 and $42 \mathrm{ka}$, and the third age of the basal strata was ca. $80 \mathrm{ka}$. However the $D_{\mathrm{e}}$ value of the third sample was high (ca. 318 Gy) considering that it was obtained using quartz, and recent publications suggest that such large $D_{\mathrm{e}}$ values in quartz may underestimate

*Correspondence: Xiaomei Nian, as above.

E-mail: xmnian@sklec.ecnu.edu.cn the true age (e.g. Wintle and Murray, 2006; Buylaert et al., 2007; Qin and Zhou, 2009; Lai, 2010; Chapot et al., 2012; Timar-Gabor and Wintle, 2013). In 2013, a 12-m² excavation pit was exposed and nearly $9 \mathrm{~m}$ of the archaeological sequence was revealed, with more than 1700 stone artefacts and 300 fauna remains. We systematically collected eight samples through the sequence of the Yangshang site, and OSL dating techniques on quartz and polymineral subsamples were used to constrain the chronology of the site, which could shed new light on our understanding of hominin behaviour and environment, including land use patterns.

\section{Site description and sampling}

The profile of the Yangshang site, with a thickness of ca. $9 \mathrm{~m}$, was divided into 11 distinct sediment layers and six cultural layers (CL) based on colour changes/particle size variations of the sediments and human remains. Eleven stratigraphic layers were numbered 1 to 11 from top to bottom (Fig. 2a): (1) modern soils; (2) brownish black silt clay; (3) brownish black silt clay with clay particles; (4) brownish black silty clay with carbonate nodules, and bearing few stone-artefacts (CL1); (5) yellowish brown silty clay with carbonate pseudomycelia, and bearing few stone-artefacts and animal fossils (CL2); (6) brown silty clay bearing abundant stone-artefacts and some animal fossils (CL3); (7) dull yellowish brown silty clay with carbonate nodules, and bearing abundant stone-artefacts and some animal fossils (CL4); (8) dull reddish brown silty clay with granular structure, and bearing abundant stone-artefacts and some animal fossils (CL5); (9) bright reddish brown silty clay with few stone-artefacts (CL6), and the lower part of the layer with no archaeological material; (10) yellowish silty clay; and (11) yellowish silty clay with green clay particles, carbonate nodules and snails. Among them, layers 4-9 are artefact- and fossil-bearing (CL1-6), and layers 6-8 are the 


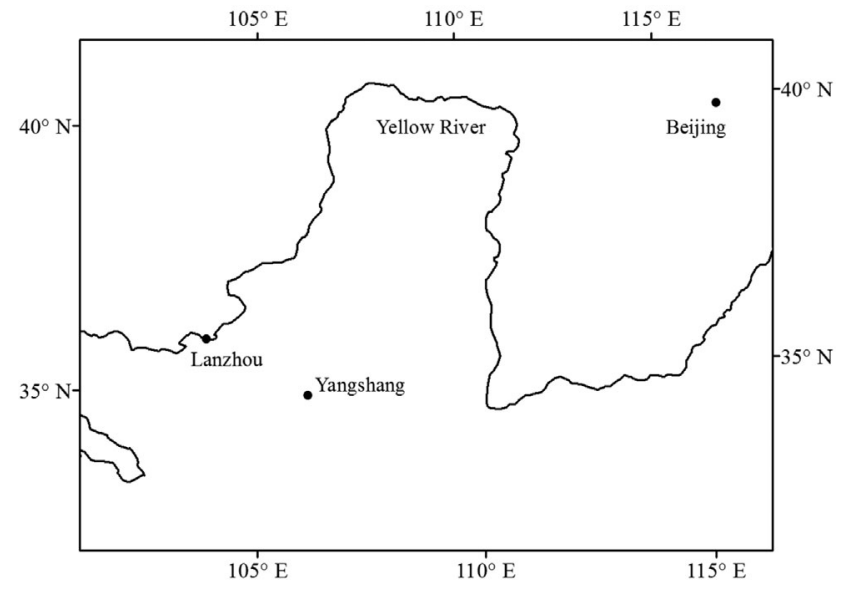

Figure 1. Map showing the geographical location of the Yangshang site.

main cultural layers (CL3-5). The sediments at the Yangshang site containing archaeological materials are mainly loesspalaeosol deposits, and the bottom of the section is composed of lacustrine sediment (layers 10-11 are lacustrine). Thirty-five stone artefacts from CL1, eight stone artefacts from CL2, 1602 stone artefacts from the main cultural layers (CL3-5), and 51 stone artefacts from CL6 were unearthed. The stone artefacts from different cultural layers show roughly similar typological features. The stone artefacts consist of hammerstones, manuports, irregular cores, discoid cores, flakes, chunks, debris and retouched tools. Most of the artefacts were manufactured from quartz, quartzite and granite obtained as well-rounded pebbles from nearby river banks. Hard hammer percussion seems to have been the dominant technique for detaching flakes. In terms of the retouched tool inventory, all assemblages from the Yangshang site are clearly flake-based including denticulates, sidescrapers, points, notches and choppers, although there are some variations among the different layers. Most of the fauna elements are small bone fragments and the mammal component of the fauna is dominated by Equus przewalskii, Cervus and Bos in general based on a few tooth counts.

\section{Methods}

Eight OSL samples were collected from the profile to provide a chronological framework of the site: seven samples (L37-L43) were collected from artefact-bearing layers (layers 4-9), and one sample (L36) was collected from layer three without archaeological materials; the approximate positions of each sample are shown as red filled stars in Fig. 2a. The grain size of the samples was analysed with a Malvern Mastersizer 2000 laser diffraction particle size analyser according to the procedure of Nian et al. (2015).

The samples for OSL dating were prepared under subdued red light. The outer layer of the sample block was cut away, and then the remaining samples were treated with hydrogen peroxide (30\%) and hydrochloric acid (10\%) to remove
Figure 2. (a) Photograph showing the Yangshang stratigraphic section and the position of the OSL samples. (b) The correlation between the OSL ages and loesspalaeosol sequence at the Yangshang site. The assignment of units L1, S1, L2 and S2 is made on the basis of the new OSL ages and also a combination of lithological characteristics (colour changes/particle size variations). Closed red circles: post-IR IRSL SAR ages; open blue circle: quartz SAR age.

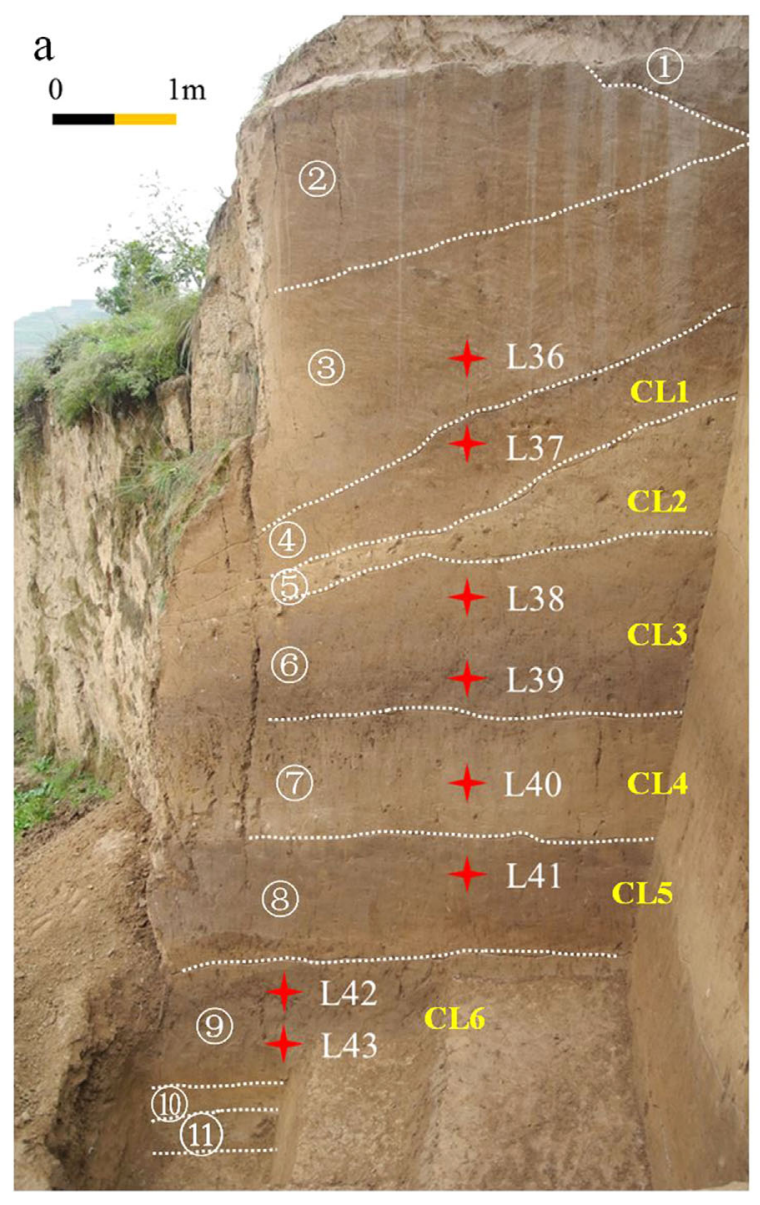

b

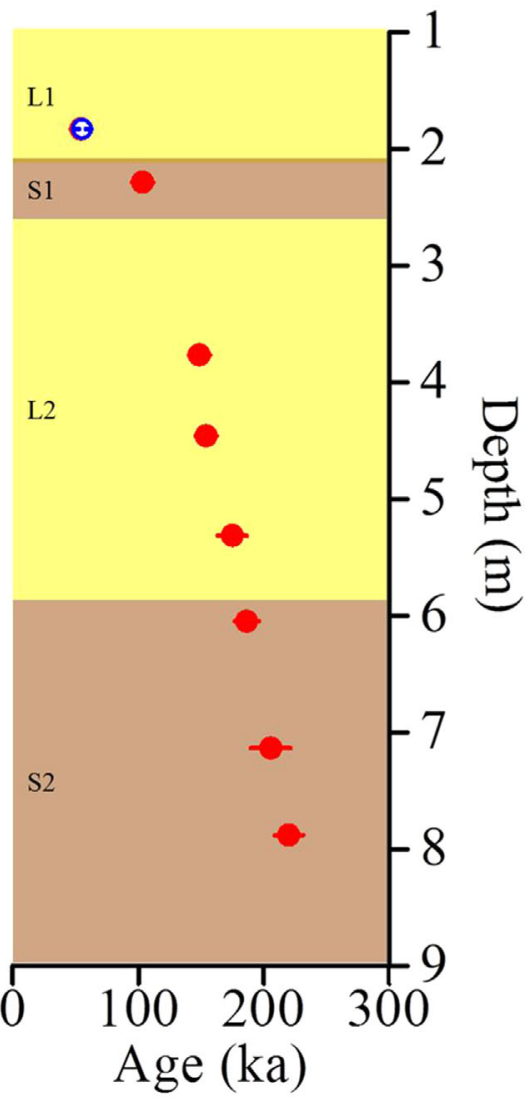


Table 1. The post-IR IRSL SAR protocol (Buylaert et al., 2012).

\begin{tabular}{llc}
\hline Step & \multicolumn{1}{c}{ Treatment } & Observed \\
\hline 1 & ${ }^{*}$ Give dose & $\mathrm{D}_{\mathrm{i}}$ \\
2 & Preheating at $320{ }^{\circ} \mathrm{C}$ for $60 \mathrm{~s}$ & \\
3 & Infrared stimulation at $50{ }^{\circ} \mathrm{C}$ for $200 \mathrm{~s}$ & $\mathrm{~L}_{\mathrm{X}}$ \\
4 & Infrared stimulation at $290{ }^{\circ} \mathrm{C}$ for $200 \mathrm{~s}$, & \\
5 & Give test dose & $\mathrm{T}_{\mathrm{X}}$ \\
6 & Preheating at $320{ }^{\circ} \mathrm{C}$ for $60 \mathrm{~s}$ & \\
7 & Infrared stimulation at $50{ }^{\circ} \mathrm{C}$ for $200 \mathrm{~s}$ & \\
8 & Infrared stimulation at $290{ }^{\circ} \mathrm{C}$ for $200 \mathrm{~s}$ & \\
9 & Infrared stimulation at $325^{\circ} \mathrm{C}$ for $100 \mathrm{~s}$ & \\
10 & Return to 1 &
\end{tabular}

*For the natural sample, $i=0, D_{i}=0$.

organic material and carbonates, respectively. Mediumgrained $(45-63 \mu \mathrm{m})$ polymineral grains were obtained by sieving, and the samples were then etched with $30 \%$ silicasaturated hydrofluorosilicic acid $\left(\mathrm{H}_{2} \mathrm{SiF}_{6}\right)$ twice, for 2 days each time to remove all non-quartz materials, and the remnant quartz components were washed in $10 \% \mathrm{HCl}$ and distilled water to dissolve acid fluoride precipitates, respectively. Infrared (IR) stimulation and the $110^{\circ}$ $\mathrm{C}$ thermoluminescence $(\mathrm{TL})$ peak of the isolated quartz were used to check the purity.

Luminescence measurements were made with an automated Risø-TL/OSL-20 reader equipped with a calibrated ${ }^{90} \mathrm{Sr} /{ }^{90} \mathrm{Y}$ beta source (Bøtter-Jensen et al., 2003), and the signals were detected by an EMI 9235QA photomultiplier tube. Blue light LED stimulation $(470 \pm 30 \mathrm{~nm})$ set at $90 \%$ of $50 \mathrm{~mW} \mathrm{~cm}^{-2}$ full power and a 7.5-mm Hoya U-340 filter (290-370 nm) were used for the quartz OSL measurements. Polyminerals were stimulated with IR diodes $(870 \pm 40 \mathrm{~nm})$ set at $90 \%$ of $140 \mathrm{~mW} \mathrm{~cm}^{-2}$, and the luminescence was detected with a combination of Schott BG39/Corning 7-59 emission filters. $U, T h$ and $K$ contents on sub-samples from each block were determined using neutron activation analysis (NAA) (Table 1). An a-value of $0.04 \pm 0.02$ for quartz and $0.08 \pm 0.02$ for feldspar (Rees-Jones, 1995) were adopted to estimate the external alpha dose rate calculation, and the internal dose rate for K-feldspars was estimated by assuming a K concentration of $12.5 \pm 0.5 \%$ (Huntley and Baril, 1997). The water content was assumed to be $20 \pm 5 \%$ for all the samples in the estimation of the dose rate. The dose rate and OSL ages were calculated using DRAC (Durcan et al., 2015).

The single aliquot regenerative dose (SAR) protocol (Murray and Wintle, 2000) was applied to the quartz OSL measurement, $260{ }^{\circ} \mathrm{C}$ preheat for $10 \mathrm{~s}$ and $220{ }^{\circ} \mathrm{C}$ cut-heat for $0 \mathrm{~s}$ were used, and quartz OSL samples were stimulated by blue light at $125^{\circ} \mathrm{C}$ for $40 \mathrm{~s}$. The initial $0.48 \mathrm{~s}$ of the OSL signals subtracting the average early background (EBG) of $0.96-1.44 \mathrm{~s}$ was used for all dose calculations recommended by Ballarini et al. (2007). Furthermore, a post-IR infrared stimulated luminescence (IRSL) SAR protocol (Thiel et al., 2011) was used to measure the equivalent dose (Table 1). At the end of each cycle, an infrared stimulation at $325^{\circ} \mathrm{C}$ for $100 \mathrm{~s}$ was applied to prevent signal build-up. The heating rate used throughout was $5{ }^{\circ} \mathrm{Cs}^{-1}$. The post-IR IRSL signals of the first $2 \mathrm{~s}$, after subtracting the background taken as the average of the last $20 \mathrm{~s}$, were integrated and used for $D_{\mathrm{e}}$ determination. Dose-response curves were fitted to an exponentialplus-linear function for the interpolation of $D_{\mathrm{e}}$.

\section{Results}

The grain size distributions of the sediments are displayed in Supplementary Information, Fig. S1. The results showed that median diameters of the samples ranged from 10 to $17 \mu \mathrm{m}$. Medium-grained quartz and polymineral fractions extracted from eight samples were used for the OSL measurements.

\section{Quartz SAR-OSL dating}

A linearity test was carried out on sample L36, i.e. a fixed regenerative dose (181.5 Gy) with 18.15 Gy test dose was repeated for eight cycles to check the sensitivity change with repeated heating and measurements (Murray and Wintle, 2000). The regenerative and test dose OSL signals showed a linear relationship, indicating that changes in the sensitivity of the signals from regeneration doses correlated well with those from the test dose (Fig. S2). A dose recovery experiment (Murray and Wintle, 2003) was applied to sample L36 that

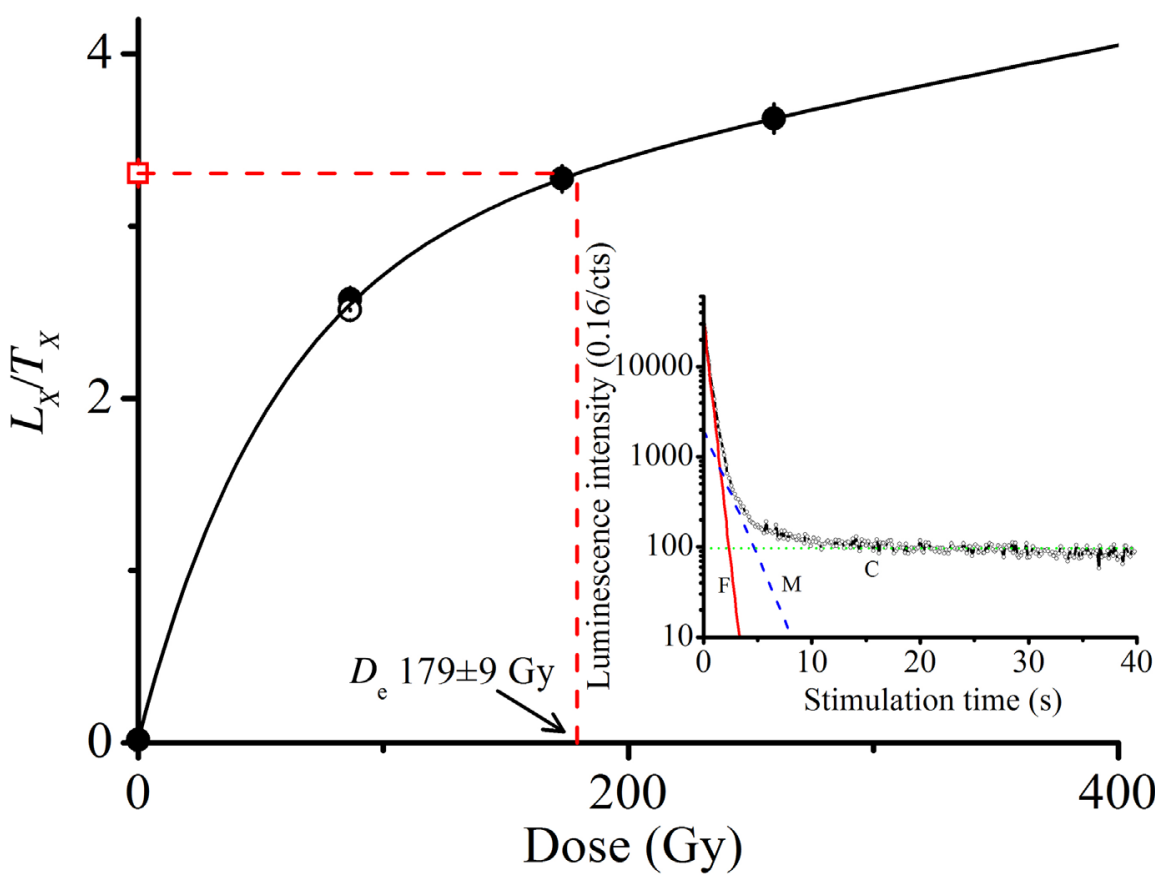

Figure 3. Dose-response curve obtained using the SAR protocol for medium-grained quartz sample L36; the inset figure shows component separation of CW-OSL signals from natural quartz grains for the corresponding sample. Closed and open circles: regenerative dose and repeated regenerative dose; open square: natural dose; $\mathrm{F}, \mathrm{M}$, and $\mathrm{C}$ are the fast, medium and constant components, respectively. 
was bleached under sunny daylight for $6 \mathrm{~h}$ on the roof and then given 181.5 Gy laboratory dose with a test dose of $18.15 \mathrm{~Gy}$; the dose recovery ratio (recovered/given dose) was $1.03 \pm 0.05(n=5)$. The recycling ratios and recuperation values of all data were within $10 \%$ of unity and were below $5 \%$, respectively. Component separation of continuous wave OSL (CW-OSL) signals from natural quartz grains is shown in Fig. 3. Results indicated that the fast and medium components contributed about 93 and $7 \%$ of the total signal, respectively, and the contribution from the slow component was negligible in the initial $0.48 \mathrm{~s}$ CW-OSL signal. The above results showed that the OSL signals were suitable for optical dating and the results for the quartz SAR-OSL measurements are shown in Table 2.

The $D_{\mathrm{e}}$ value of sample L36 was $177 \pm 5 \mathrm{~Gy}$, and the corresponding age was $55 \pm 3 \mathrm{ka}$. For the other seven samples from the cultural layer, the quartz SAR-OSL ages were between $72 \pm 7$ and $111 \pm 18 \mathrm{ka}$, and the corresponding $D_{\mathrm{e}}$ values ranged from $246 \pm 23$ to $413 \pm 64$ Gy, with a minimum of three aliquots for each sample (Table 2). The ages of these samples exceeded the quartz dating limit using the SAR protocol (e.g. Wintle and Murray, 2006; Buylaert et al., 2007; Qin and Zhou, 2009; Lai, 2010; Chapot et al., 2012; Timar-Gabor and Wintle, 2013) as mentioned above, which may result in age underestimation. Therefore, we decided to investigate and measure the feldspar signals to extend the luminescence chronology at Yangshang.

\section{Feldspar post-IR IRSL SAR dating}

The lower saturation of quartz OSL signal restricts the application to old samples, but feldspar has a higher saturation dose and brighter signal than quartz. However, the luminescence signal of feldspars usually suffers anomalous fading, which leads to an underestimation in age (Wintle, 1973). Recent studies showed that IR stimulation of feldspar at elevated temperature can reduce or even eliminate laboratory fading rates of the IRSL signal in the blue region of the spectrum (Jain and Singhvi, 2001; Thomsen et al., 2008), and introduced the post-IR IRSL SAR protocol (Buylaert et al., 2009, 2012; Thiel et al., 2011), so feldspar has been increasingly used in recent years for estimating the depositional age of Quaternary sediments. In the post-IR IRSL SAR protocol, the aliquots were stimulated with IR at a lower temperature (IR $50^{\circ} \mathrm{C}$ ) to remove more easy-to-fade signals, and a second IR stimulation at an elevated temperature (pIRIR $290{ }^{\circ} \mathrm{C}$ ) was then able to access a more stable luminescence signal to permit dating of older samples using feldspar signals.

A dose recovery test with different test doses, 78.65 Gy ( $13 \%$ of the given dose), 181.5 Gy (30\% of the given dose), 363 Gy $(60 \%$ of the given dose) and 471.9 Gy $(78 \%$ of the given dose), was carried on sample L40, that was bleached by sunny-day light for $10 \mathrm{~h}$ on the roof and then given 605 Gy laboratory dose (Table 1). For these four different test doses, the residual doses were approximately 16, 12, 14 and 11 Gy using two aliquots for each test dose, respectively. There is no significant difference in these values and the residual is small compared to the natural dose, so the average of these residual doses for different test doses ( $13 \pm 4$ Gy) was used. This average residual was subtracted from all recovered doses. Figure 4 shows that the recovery ratio (recovered/given dose) decreased from $1.43 \pm 0.06$ to $1.06 \pm 0.05$ as the test dose increased from 78.65 to 471.9 Gy. The recycling ratios and recuperation values were within $0.9-1.1$ and $<5 \%$, respectively. The $D_{\mathrm{e}}$ of this sample also showed a decrease in value $(918 \pm 54$ to $740 \pm 38 \mathrm{~Gy})$ as the test dose increased (Fig. 4a).

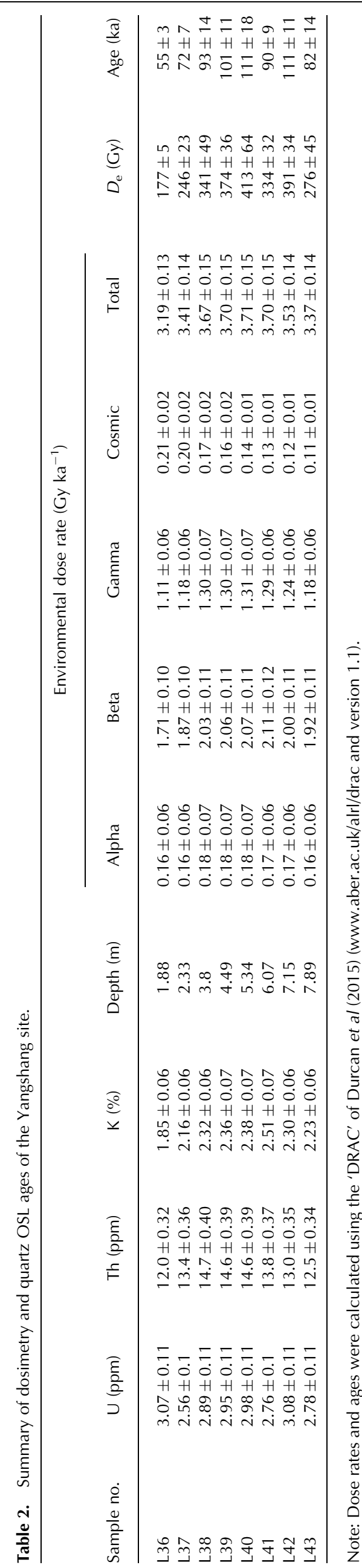

J. Quaternary Sci., Vol. 31(8) 928-935 (2016) 

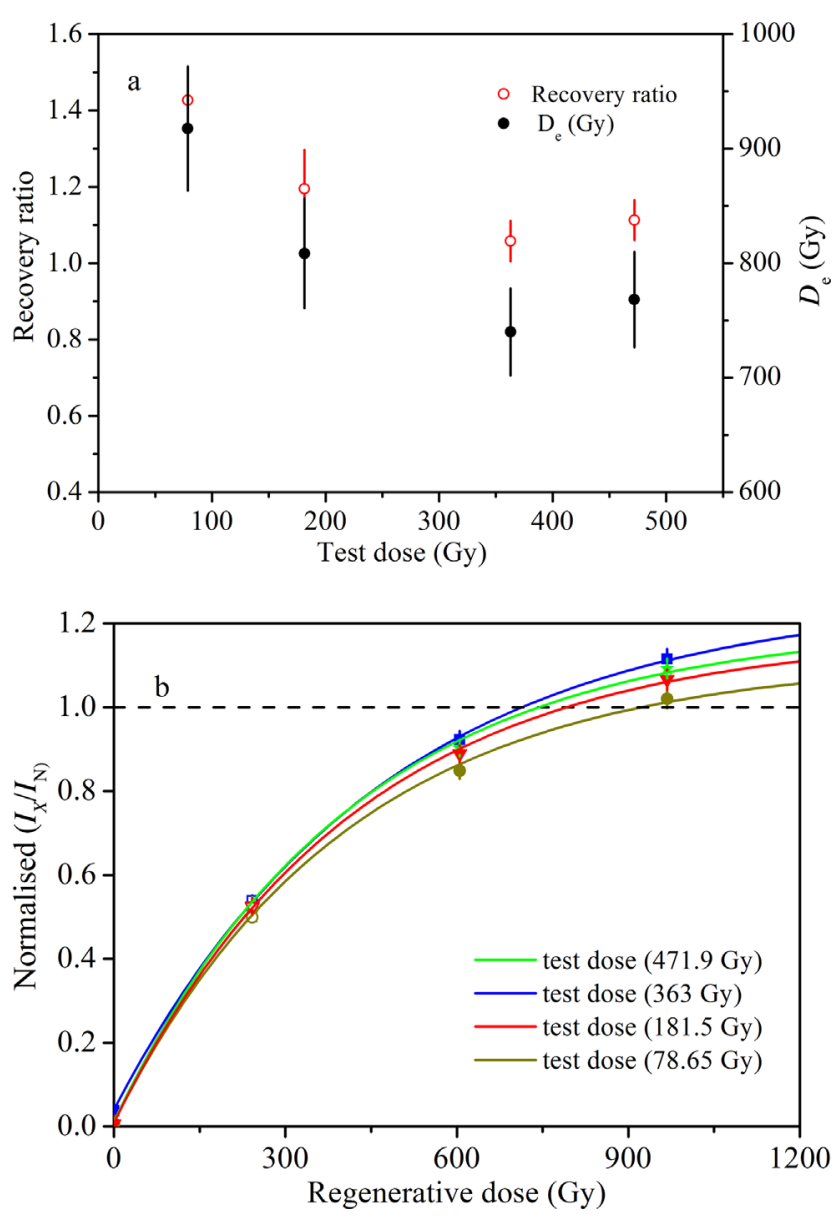

Figure 4. (a) The relationship of recovery ratio/ $D_{\mathrm{e}}$ values and different sizes of test doses $(78.65,181.5,363,471.9 \mathrm{~Gy})$ for sample L40, and the grains for the dose recovery test were bleached by sunny-day light for $10 \mathrm{~h}$. Open symbols: recovery ratio; closed symbols: $D_{\mathrm{e}}(\mathrm{Gy})$. (b) Four dose-response curves obtained with the post-IR IRSL protocol for sample L40. Corrected luminescence intensity $\left(I_{X}=L_{X} / T_{X}\right)$ was normalized to the natural signal intensity $\left(I_{N}\right)$, and the dashed line represents corrected natural luminescence intensity. Symbols and lines in different colours represent different test doses from 78.6 to $471.9 \mathrm{~Gy}$. Closed and open symbols represent regenerative doses and recycled dose, respectively.

For the protocol in Table 1, when steps 1-4 were finished, steps 2-4 (preheating at $320^{\circ} \mathrm{C}$ for $60 \mathrm{~s}$ followed by IR stimulation at $50{ }^{\circ} \mathrm{C}$ and post-IR IRSL stimulation at $290{ }^{\circ} \mathrm{C}$ for $60 \mathrm{~s}$ ) were repeated once (step $2^{\prime}, 3^{\prime}, 4^{\prime}$ ) to monitor the thermal transfer post-IR IRSL signal (step $4^{\prime}$ ). Significant thermal transfer post-IR IRSL signals were observed as has previously been seen, and which have an influence on the final ages of the samples (Nian et al., 2009, 2012; Qin and Zhou, 2012) (Fig. 5a). As shown in Fig. 5b, the size of the normalized thermal transfer post-IR IRSL signals $\left(T_{x} / T_{x}\right)$ from natural signals and those from a fixed regenerative dose $(605$ Gy) varied with the size of the test dose. The normalized thermal transfer post-IR IRSL $\left(\mathrm{TT}_{\chi} / \mathrm{T}_{\chi}\right)$ decreased as the test dose increased; in other words, the contribution of thermal transfer to $T_{X}$ decreased with increasing test dose.

The post-IR IRSL SAR protocol which used higher stimulation temperature promised new hope for OSL dating of feldspar, but thermally transferred post-IR IRSL signal was found in the sample during the measurement process. A large test dose $(60 \%$ of the given dose) can reduce the effect of the thermally transferred signals in the post-IR IRSL protocol. In this study, measurements of $D_{\mathrm{e}}$ used a test dose of 123 Gy for sample L36, 236 Gy for sample L37, 363 Gy for samples L38-40, and 461 Gy for samples L41-43. For each sample,
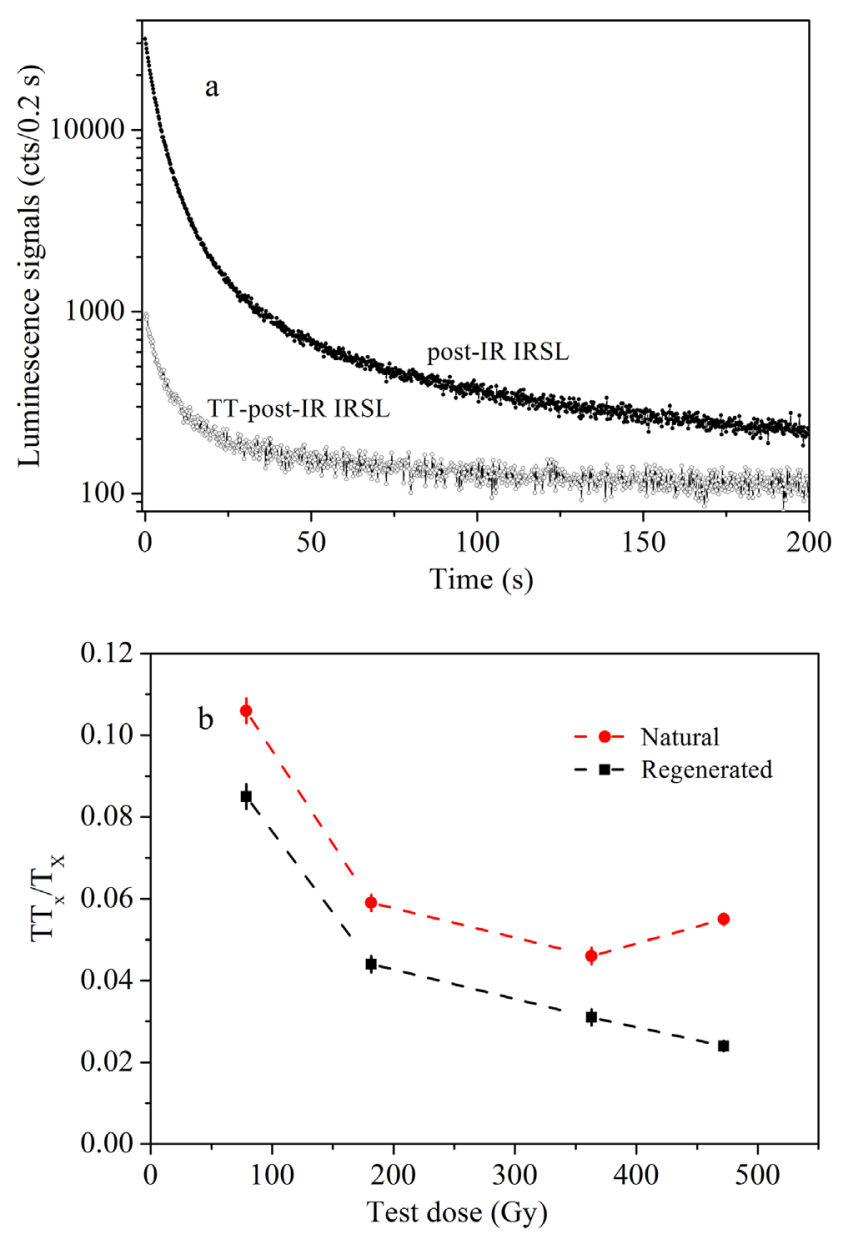

Figure 5. (a) Example natural post-IR IRSL and thermal transfer postIR IRSL decay curves of sample L40. (b) The proportion of thermal transfer post-IR IRSL signals from natural/regenerative dose (605 Gy) to different sizes of test doses (78.65, 181.5, 363, 471.9 Gy) (L40). Closed circle and square represent natural and regenerative doses, respectively. The same discs were used to measure $T T_{X} / T_{X}$ ratios of the natural and regenerative doses with the same test doses; $T T_{X} / T_{X}$ ratios of the regenerative dose were measured following a cut-heat of $450{ }^{\circ} \mathrm{C}$ after the measurement of natural $\mathrm{TT}_{\mathrm{X}} / \mathrm{T}_{\mathrm{X}}$ ratios.

the residual of $13 \pm 4$ Gy measured for the dose recovery experiment was subtracted from the average $D_{\mathrm{e}}$ to determine the value used to estimate the final ages of the samples.

The rate of anomalous fading of the post-IR IRSL signal was investigated for the samples. After $D_{\mathrm{e}}$ determination the aliquots were irradiated with a fixed dose (605 Gy) in the laboratory and preheated. After different storage times in the dark, the sensitivity-corrected IR $50{ }^{\circ} \mathrm{C}$ and pIRIR $290^{\circ}$ C signals were measured. A typical example of fading rate measurements for sample L40 is shown in Fig. 6. The results showed no apparent change in intensity of the post-IR IRSL signal with storage time from several hours to several days after irradiation, and the normalized values fluctuated between 0.9 and 1.1 . The average $g_{2 \text { days }}$ value (pIRIR $290{ }^{\circ} \mathrm{C}$ ) was $-0.36 \pm 0.16 \% /$ decade $(n=3)$ for sample L 40 .

Based on post-IR IRSL SAR dating with medium-grained polymineral, we found that the ages of the Yangshang site varied from ca. 104 to ca. $220 \mathrm{ka}$, corresponding to Marine Isotope Stage (MIS) 5, 6 and 7 (Table 3; Fig. 2b), indicating that ancient humans have occupied this area within the period. The post-IR IRSL SAR ages for two samples L42 and L43 from CL6 were $206 \pm 16$ and $220 \pm 11 \mathrm{ka}$, respectively. The ages of samples from main cultural layers (CL3-5, L38-41) were $149 \pm 9,154 \pm 8,175 \pm 12$ and $186 \pm 10 \mathrm{ka}$. These ages cover the period corresponding to deposition of 
Figure 6. Fading rate measurements for the post-IR IRSL signal at $290^{\circ} \mathrm{C}$ (given dose: 605 Gy, test dose: 363 Gy). The values were normalized to the first measurement.

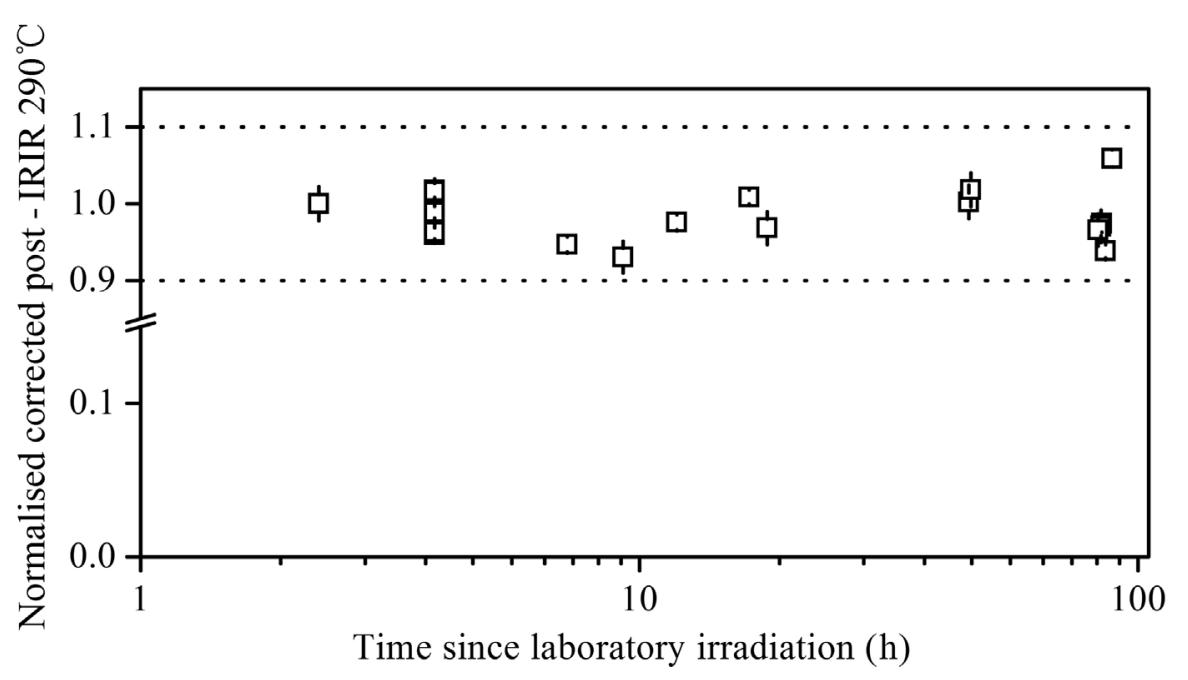

S2 and L2 in the Chinese Loess Plateau (Ding et al., 2002). In the Chinese Loess Plateau, the L2 loess unit is composed of three typical loess layers (L2-1, L2-3 and L2-5) and two weakly developed soils (L2-2 and L2-4), suggesting climate instability during the penultimate glaciation (Yang and Ding, 2003). Based on the new OSL ages and the sedimentary characteristics of the sediment, brown silty clay of layer 7 (CL4) and layer 6 (CL3) correspond to loess unit L2-5 and the weakly developed soil units L2-4. CL1 (L37) yielded an age of $104 \pm 5 \mathrm{ka}$. The age of sample L36 from the upper cultural layer was $54 \pm 3 \mathrm{ka}$, which agreed with the quartz SAR-OSL age $(55 \pm 3 \mathrm{ka})$ within experimental errors. The above results were based on eight aliquots for each sample. These ages are internally stratigraphically consistent, suggesting the age estimates of the samples are reliable.

\section{Discussion and conclusions}

As shown above, quartz OSL dating results from the cultural layers may be beyond the upper limit of the method. Consequently, the post-IR IRSL SAR protocol was applied to medium-grained polyminerals to estimate the chronology of the site. However, unwanted thermal transfer signals may be generated in the post-IR IRSL signal due to preheat and stimulation at high temperature, but a large test dose was used to reduce the effect of these thermally transferred signals. The post-IR IRSL SAR protocol gave us confidence in extending the dating range. The elevated temperature post-IR IRSL signals of feldspar with high saturation dose have great potential to provide reliable chronologies for relatively old archaeological sites.

From the presently observed stratigraphy (Fig. 2) and the chronology of the sediments (Tables 2 and 3), we find that a considerable thickness of layers $3-5$ could have been eroded. The previous ages published by Morgan et al. (2011) were $40.7 \pm 3.1$ and $42.1 \pm 3.9 \mathrm{ka}$, and these two samples may be collected from a stratum equal to a part of layer 3, with an age slightly younger than $54 \pm 3 \mathrm{ka}$ (sample L36). The third sample from the basal level of the deposit yielded an age of $80.1 \pm 6.6$ ka using quartz signals, which is likely to be beyond the upper limit of reliable quartz OSL dating and could therefore be an underestimation.

Based on OSL dating results using the post-IR IRSL SAR protocol, a Palaeolithic chronology spanning a range from ca. 104 to $220 \mathrm{ka}$ has been established at the Yangshang site. Our ages for the Yangshang site occur during the warmer and humid period when S1 and S2 were deposited on the Chinese Loess Plateau, and the cold period when L2 was formed as part of the loess-palaeosol sequence. The new dating results demonstrate ancient hominins occupied this area earlier than previously thought. The duration of occupation is longer and the density of archaeological materials is higher than proposed by Morgan et al. (2011). As a consequence, human settlement patterns proposed by Morgan et al. (2011) in the western Loess Plateau should be re-evaluated.

The Yangshang site was mainly dated to a period from 104 to $220 \mathrm{ka}$, which is a critical time span to discussions on the 'Middle Palaeolithic' in China (Gao, 1999; Gao and Norton,

Table 3. The post-IR IRSL SAR dating results of the samples.

Environmental dose rate $\left(\mathrm{Gy} \mathrm{ka}{ }^{-1}\right)$

\begin{tabular}{|c|c|c|c|c|c|c|c|c|}
\hline \multicolumn{4}{|c|}{ External } & \multirow[b]{2}{*}{ Internal } & \multirow[b]{2}{*}{ Total } & \multirow[b]{2}{*}{$D_{\mathrm{e}}(\mathrm{Gy})$} & \multirow[b]{2}{*}{ Over-dispersion } & \multirow[b]{2}{*}{ Age (ka) } \\
\hline Alpha & Beta & Gamma & Cosmic & & & & & \\
\hline $0.45 \pm 0.10$ & $1.72 \pm 0.10$ & $1.11 \pm 0.06$ & $0.21 \pm 0.02$ & $0.19 \pm 0.03$ & $3.68 \pm 0.15$ & $200 \pm 6$ & $0.06 \pm 0.02$ & $54 \pm 3$ \\
\hline $0.45 \pm 0.10$ & $1.88 \pm 0.10$ & $1.18 \pm 0.06$ & $0.20 \pm 0.02$ & $0.19 \pm 0.03$ & $3.90 \pm 0.16$ & $404 \pm 7$ & $0.04 \pm 0.02$ & $104 \pm 5$ \\
\hline $0.49 \pm 0.11$ & $2.04 \pm 0.11$ & $1.30 \pm 0.07$ & $0.17 \pm 0.02$ & $0.19 \pm 0.03$ & $4.19 \pm 0.17$ & $623 \pm 25$ & $0.05 \pm 0.04$ & $149 \pm 9$ \\
\hline $0.50 \pm 0.11$ & $2.07 \pm 0.11$ & $1.30 \pm 0.07$ & $0.16 \pm 0.02$ & $0.19 \pm 0.03$ & $4.22 \pm 0.17$ & $651 \pm 21$ & $0.05 \pm 0.03$ & $154 \pm 8$ \\
\hline $0.50 \pm 0.11$ & $2.09 \pm 0.12$ & $1.31 \pm 0.07$ & $0.14 \pm 0.01$ & $0.19 \pm 0.03$ & $4.23 \pm 0.18$ & $740 \pm 38$ & $0.07 \pm 0.03$ & $175 \pm 12$ \\
\hline $0.47 \pm 0.10$ & $2.13 \pm 0.12$ & $1.29 \pm 0.06$ & $0.13 \pm 0.01$ & $0.19 \pm 0.03$ & $4.20 \pm 0.17$ & $783 \pm 24$ & $0.09 \pm 0.04$ & $186 \pm 10$ \\
\hline $0.47 \pm 0.10$ & $2.02 \pm 0.11$ & $1.24 \pm 0.06$ & $0.12 \pm 0.01$ & $0.19 \pm 0.03$ & $4.04 \pm 0.17$ & $830 \pm 53$ & $0.15 \pm 0.05$ & $206 \pm 16$ \\
\hline $0.44 \pm 0.10$ & $1.93 \pm 0.11$ & $1.18 \pm 0.06$ & $0.11 \pm 0.01$ & $0.19 \pm 0.03$ & $3.85 \pm 0.16$ & $847 \pm 26$ & $0.11 \pm 0.03$ & $220 \pm 11$ \\
\hline
\end{tabular}

Note: Dose rates and ages were calculated using the 'DRAC' of Durcan et al (2015) (www.aber.ac.uk/alrl/drac and version 1.1). 
2002; Kei, 2012; Li, 2014). In terms of lithic technology, the assemblage at Yangshang is similar to those from Zhoukoudian locality 15 (Gao, 2000, 2001), one of the contemporary sites, but lacking large cutting tools, such as cleavers. Considering the variations of lithic assemblages from 104 to 220 ka in North China is a better way to understand lithic technology regionally ( $\mathrm{Li}, 2014)$. The new dating results and the detailed analysis on lithic materials in the future from Yangshang will add more data for us understanding the mysterious Chinese Middle Palaeolithic period. As has been amply demonstrated in the previous studies, the Middle Pleistocene has experienced great climate variability of predominant 100 ka glaciation cycles, and glacial periods lasted relatively longer than interglacial periods (e.g. Lisiecki and Raymo, 2005). The responses of hominins to the cycles of glaciation are very important to discussions of human evolution. The luminescence dating results demonstrated that ancient hominins occupied the western Loess Plateau of China at the Yangshang site at least during MIS 7, and persisted through the cold stage MIS 6, and until MIS 5 . The site has provided a relatively high-resolution Palaeolithic sequence for discussing interactions between human behaviour and environment which will be addressed in future studies.

Acknowledgements. Thanks to two anonymous reviewers and the editors of the journal whose detailed reviews and suggestions led to many improvements in the manuscript. The excavation at the Yangshang site is a part of a collaborative research programme between Institute of Vertebrate Paleontology and Paleoanthropology, Chinese Academy of Sciences, and Gansu Provincial Institute of Archaeology and Cultural Relics. The success of this project is attributable in large part to the efforts of Prof. Hui Wang and Prof. Xing Gao. This work was supported by the National Natural Science Foundation of China (grant no. 41302135; grant no. 41272032), the China Postdoctoral Science Foundation (grant no. 2015M571521), and the Ministry of Science and Technology of China (2014RCDW02).

\section{Supporting Information}

Additional supporting information may be found in the online version of this article.

Figure S1. Grain size distribution of the samples from the Yangshang site.

Figure S2. Plot of regenerative dose OSL signals versus test dose OSL signals using the SAR protocol for sample L36.

Abbreviations. IRSL, infrared stimulated luminescence; MIS, Marine Isotope Stage; OSL, optically stimulated luminescence; SAR, single aliquot regenerative.

\section{References}

Aitken MJ. 1998. An Introduction to Optical Dating. Oxford University Press: New York.

An ZS, Liu TS, Lu YC et al. 1990. The long-term Peleomonsoon variation recorded by the loess-paleosol sequence in central China. Quaternary International 7-8: 91-95.

Ballarini M, Wallinga J, Wintle AG et al. 2007. A modified SAR protocol for optical dating of individual grains from young quartz samples. Radiation Measurements 42: 360-369.

Bøtter-Jensen L, Andersen CE, Duller GAT et al. 2003. Developments in radiation, stimulation and observation facilities in luminescence measurements. Radiation Measurements 37: 535-541.

Buylaert JP, Jain M, Murray AS et al. 2012. A robust feldspar luminescence dating method for Middle and Late Pleistocene sediments. Boreas 41: 435-451.

Buylaert JP, Murray AS, Thomsen KJ et al. 2009. Testing the potential of an elevated temperature IRSL signal from K-feldspar. Radiation Measurements 44: 560-565.
Buylaert JP, Vandenberghe D, Murray AS et al. 2007. Luminescence dating of old $(>70 \mathrm{ka}$ ) Chinese loess: A comparison of singlealiquot OSL and IRSL techniques. Quaternary Geochronology 2: 9-14.

Chapot MS, Roberts HM, Duller GAT et al. 2012. A comparison of natural- and laboratory-generated dose response curves for quartz optically stimulated luminescence signals from Chinese Loess. Radiation Measurements 47: 1045-1052.

Ding ZL, Derbyshire E, Yang SL et al. 2002. Stacked 2.6-Ma grain size record from the Chinese loess based on five sections and correlation with the deep-sea $\delta^{18} \mathrm{O}$ record. Paleoceanography 17: $5-1$.

Durcan JA, King GE, Duller GAT. 2015. DRAC: Dose rate and age calculation for trapped charge dating. Quaternary Geochronology 28: 54-61. (DRAC_1.1, www.aber.ac.uk/alrl/drac).

Gao X. 1999. A discussion on 'Chinese Middle Paleolithic'. Acta Anthropologica Sinica 18: 1-15 [in Chinese with English abstract].

Gao X. 2000. A study of flaking technology at Zhoukoudian locality 15. Acta Anthropologica Sinica 19: 199-215 [in Chinese with English abstract].

Gao X. 2001. A study of stone tools typology and retouch technology at Zhoukoudian locality 15. Acta Anthropologica Sinica 20: 1-18.

Gao X, Norton CJ. 2002. A critique of the Chinese 'Middle Palaeolithic'. Antiquity 76: 397-412.

Huntley DJ, Baril MR. 1997. The K content of the K-feldspars being measured in optical dating or in thermoluminescence dating. Ancient TL 15: 11-13.

Huntley DJ, Godfrey-Smith DI, Thewalt MLW. 1985. Optical dating of sediments. Nature 313: 105-107.

Jain M, Singhvi AK. 2001. Limits to depletion of blue-green light stimulated luminescence in feldspars: implications for quartz dating. Radiation Measurements 33: 883-892.

Kei YM. 2012. The Middle Palaeolithic in China: a review of current interpretations. Antiquity 86: 619-626.

Lai ZP. 2010. Chronology and the upper dating limit for loess samples from Luochuan section in the Chinese Loess Plateau using quartz OSL SAR protocol. Journal of Asian Earth Sciences 37: 176-185.

Li F. 2014. Fact or fiction: the Middle Palaeolithic in China. Antiquity 88: 1303-1309.

Lisiecki LE, Raymo ME. 2005. A Pliocene-Pleistocene stack of 57 globally distributed benthic $\delta^{18} \mathrm{O}$ records. Paleoceanography 20: PA 1003.

Liu TS. 1985. Loess and the Environment. China Ocean Press: Beijing.

Morgan C, Barton L, Bettinger R et al. 2011. Glacial cycles and Palaeolithic adaptive variability on China's Western Loess Plateau. Antiquity 85: 365-379.

Murray AS, Wintle AG. 2000. Luminescence dating of quartz using an improved single-aliquot regenerative-dose protocol. Radiation Measurements 32: 57-73.

Murray AS, Wintle AG. 2003. The single aliquot regenerative dose protocol: potential for improvements in reliability. Radiation Measurements 37: 377-381.

Nian XM, Bailey RM, Zhou LP. 2012. Investigations of the post-IR IRSL protocol applied to single K-feldspar grains from fluvial sediment samples. Radiation Measurements 47: 703-709.

Nian XM, Chen FY, Li F et al. 2015. Optical dating of a Paleolithic site near the eastern coastal region of Shandong, northern China. Quaternary Geochronology 30: 466-471.

Nian XM, Zhou LP, Qin JT. 2009. Investigation of the post-IR IRSL signal of K-feldspar using a sediment sample below the Brunhes/ Matuyama Boundary. In Second Asia Pacific Conference on Luminescence and Electron Spin Resonance Dating. Ahmedabad, pp. 87.

Qin JT, Zhou LP. 2009. Stepped-irradiation SAR: a viable approach to circumvent OSL equivalent dose underestimation in last glacial loess of northwestern China. Radiation Measurements 44: 417-422.

Qin JT, Zhou LP. 2012. Effects of thermally transferred signals in the post-IR IRSL SAR protocol. Radiation Measurements 47: 710-715.

Rees-Jones J. 1995. Optical dating of young sediments using finegrain quartz. Ancient TL 13: 9-14. 
Rhodes EJ. 2011. Optically stimulated luminescence dating of sediments over the past 200, 000 years. Annual Review of Earth and Planetary Sciences 39: 461-488.

Roberts HM. 2008. The development and application of luminescence dating to loess deposits: a perspective on the past, present and future. Boreas 37: 483-507.

Thiel C, Buylaert JP, Murray A et al. 2011. Luminescence dating of the Stratzing loess profile (Austria) - Testing the potential of an elevated temperature post-IR IRSL protocol. Quaternary International 234: 23-31.

Thomsen KJ, Murray AS, Jain M et al. 2008. Laboratory fading rates of various luminescence signals from feldspar-rich sediment extracts. Radiation Measurements 43: 1474-1486.
Timar-Gabor A, Wintle AG. 2013. On natural and laboratory generated dose response curves for quartz of different grain sizes from Romanian loess. Quaternary Geochronology 18: 34-40.

Wintle AG. 1973. Anomalous fading of thermo-luminescence in mineral samples. Nature 245: 143-144.

Wintle AG, Murray AS. 2006. A review of quartz optically stimulated luminescence characteristics and their relevance in single-aliquot regeneration dating protocols. Radiation Measurements 41: 369-391.

Yang SL, Ding ZL. 2003. Color reflectance of Chinese loess and its implications for climate gradient changes during the last two glacial-interglacial cycles. Geophysical Research Letters 30: 2058. 